\title{
Failure to Disconnect
}

National Cancer Institute

\section{Source}

National Cancer Institute. Failure to Disconnect. NCI Thesaurus. Code C63180.

Problem associated with the linking of the device whereby termination of the transfer of liquid, gas, electricity, or information cannot be accomplished, or linking components do not come apart, or disconnect, when expected. 